\title{
A comparison of Landsat and MODIS flood inundation maps for hydrodynamic modelling in the Murray Darling Basin
}

\author{
$\underline{\text { C. Ticehurst }}^{\text {a }}$, D. Dutta ${ }^{\text {a }}$ and J. Vaze ${ }^{a}$ \\ ${ }^{a}$ CSIRO Land and Water Flagship, Black Mountain Laboratories, Australian Capital Territory \\ Email: catherine.ticehurst@csiro.au
}

\begin{abstract}
The mapping of spatial inundation patterns during flood events is important for environmental management and disaster monitoring. Remote sensing technologies provide an affordable means of capturing flood extent with reasonable spatial and temporal coverage for flood monitoring. Landsat and MODIS are commonly used for producing flood inundation maps since they can cover large remote regions, are readily available and easy to process. Hydrodynamic modelling tools are widely used for floodplain inundation modelling to a high accuracy, but they are resource intensive, making them impractical to use for large catchments. There are also few hydrological floodplain inundation modelling tools which represent the detailed floodplain hydraulics using simplified hydrological concepts and equations partly overcoming the issues associated with hydrodynamic models for large scale applications. Remote sensing products are useful and to some extent necessary for both calibrating and validating hydrodynamic and hydrological floodplain inundation models, as well as extending the coverage. The higher spatial resolution of the Landsat data (30-m pixel size) makes it ideal for many flood mapping applications, however its temporal frequency (16 days) is not always suitable for short duration flood events. The MODIS sensors acquire imagery up to two times a day - once on the TERRA platform in the morning, and once on the AQUA platform in the afternoon however its spatial resolution ranges from $250-\mathrm{m}$ up to $1000-\mathrm{m}$, which is not ideal for fine-scale flood events. This paper performs a detailed comparison of flood maps derived from Landsat data (based on the Normalized Difference Water Index), and MODIS data (based on the Open Water Likelihood algorithm) for a number of selected flood events in the Murray Darling Basin (MDB) in Australia. It directly compares and analyses the advantages and disadvantages of both the Landsat and MODIS sensors for mapping the flood events. The outputs from MODIS and Landsat data for a selected flood event in the Murrumbidgee floodplain in the MDB are also compared to the simulated inundation results from a two-dimensional hydrodynamic model.
\end{abstract}

Keywords: Flood mapping, remote sensing, floodplain inundation 


\section{INTRODUCTION}

With flood frequency likely to increase as a result of environmental changes (Karamouz et al., 2011; Bhuiyan and Dutta, 2012; Teng et al., 2012), there is a growing demand for accurate flood maps for disaster risk management. Hydrodynamic modelling tools are widely used for floodplain inundation modelling (Dutta et al., 2007; Karim et al., 2013 \& 2015). While these tools are highly effective in producing detailed characteristics of floodplain inundation with high accuracy, they require large amounts of data for model configuration and calibration. Outputs of hydrodynamic (HD) models are highly sensitive to the spatial resolution of modelling grids, and the performance worsens as the spatial resolution decreases (Dutta and Nakayama, 2009). For large catchments or floodplains it becomes computationally expensive and time consuming to setup an accurate high spatial resolution two dimensional floodplain HD model.

Contemporary remote sensing technologies provide an affordable means of capturing flood extent with reasonable spatial and temporal coverage for flood monitoring, provided that it is at a spatial scale suited to the flood size and dynamics. Landsat imagery ( $30-\mathrm{m}$ spatial resolution) can provide the appropriate spatial detail for many water mapping applications (Ryu et al., 2002; Frazier and Page, 2000), but its temporal frequency of 16 days is not always suited to capturing the spatial dynamics of some flood events. Indices such as the Normalized Difference Water Index (NDWI) or modifications thereof are often used for mapping surface water in Landsat data (McFeeters, 1996; Xu, 2006). The MODIS sensors provide near-global spatial coverage at sub-daily intervals (1-2 times/day), however its spatial resolution (250-m - 1-km) may not always be able to show fine-scale flooding. MODIS data have been widely used for mapping surface water (Brakenridge and Anderson, 2006; Chen et al., 2014; Huang et al., 2014) and while its spatial resolution may not be ideal for mapping small water features, the spatial and temporal consistency can still be of great value in detecting general changes in water movement. The MODIS open water likelihood (OWL) has been shown to be a useful algorithm for mapping open surface water in MODIS data (Guerschman et al., 2011; Ticehurst et al, 2014). Ticehurst et al. (2013) and Chen et al. (2013) have shown that the MODIS OWL can effectively map medium to large water features when compared to an equivalent Landsat water map, but tends to underestimate water extent around the edges of the flood.

This paper focuses on the coverage and availability of Landsat (based on the NDWI) and MODIS data (based on the OWL) when monitoring two large flood events in the Murrumbidgee floodplain of the MurrayDarling Basin in south-eastern Australia. It also compares the Landsat and MODIS mapped flood extents at two flow gauge stations along the Murrumbidgee River during these flood events. The Landsat and MODIS results are then compared to spatial extents from a hydrodynamic model.

\section{THE MURRUMBIDGEE FLOODPLAIN}

The Murrumbidgee floodplain is located in the state of New South Wales in south-eastern Australia (Figure 1). It is located on the Murrumbidgee River and is a major tributary of the Murray River in the Murray-Darling Basin. Overbank flow occurs frequently in the lower Murrumbidgee floodplain which covers an area of 300,000 ha, while the mid-Murrumbidgee covers an area of 5000 ha (Teng et al., 2015). Two large floods occurred in late 2010-early 2011 and early 2012. These flood events are used to compare the Landsat, MODIS and HD model flood maps. Streamflow data was used at two sites (flow gauges 410001 and 410078) to provide information on the flood timing and magnitude.

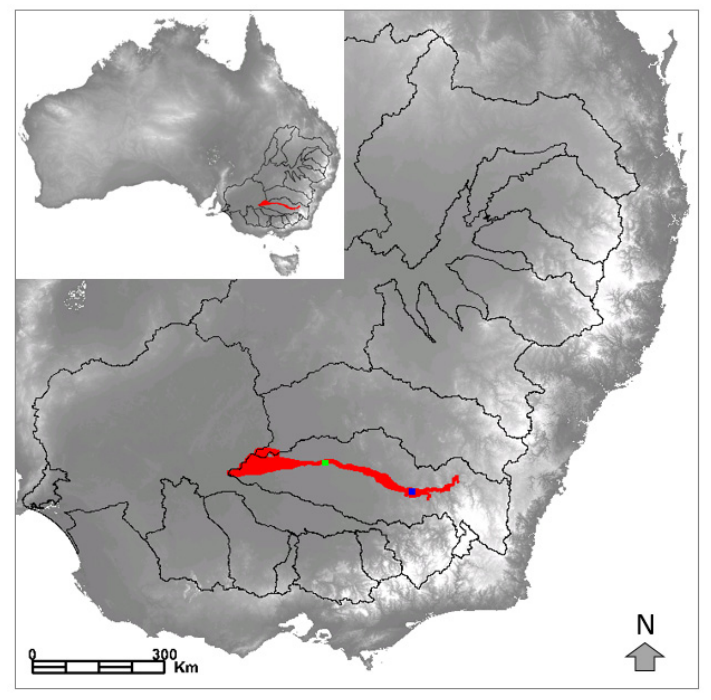

Figure 1. Location of Murrumbidgee floodplain (red) in the Murray-Darling Basin in southeastern Australia. Flow gauge sites 410001 and 410078 are shown in blue and green respectively. 


\section{DATA AND METHODS}

\subsection{Remote sensing}

The TERRA (morning overpass) and AQUA (afternoon overpass) MODIS daily surface reflectance data (named MOD09GA and MYD09GA, respectively) were used for producing the MODIS flood maps. The data were downloaded from the NASA LP DAAC (Land Processes Distributed Active Archive Centre) website: http://reverb.echo.nasa.gov/reverb. The Open Water Likelihood (OWL) algorithm (Guerschman et al., 2011) was used for mapping open surface water in the MODIS imagery. It was developed using empirical statistical modelling and calculates the fraction of water within a MODIS pixel (Guerschman et al., 2011). The MODIS OWL pixels, expressed as water fractions, are converted into water/non-water pixels for flood mapping through the selection of a water fraction threshold. This threshold was set at $5 \%$ based on Ticehurst et al. (2015).

For Landsat data, Geoscience Australia's Australian Reference Grid 25 product was used. These images have been normalized for sun angle effects to be spatially and temporally consistent (Li, 2010). Each image was inspected for cloud cover and manually masked when required. The Normalized Difference Water Index (NDWI) using: (green-MIR)/(green+NIR) (Xu, 2006) was calculated and a water mask produced. An NDWI threshold of greater than -0.3 was used to mask the NDWI image as water (Sims et al., 2014).

All MODIS (MOD and MYD) and Landsat images for the periods of $1^{\text {st }}$ November 2010 to $28^{\text {th }}$ February 2011, and $1^{\text {st }}$ March to $31^{\text {st }}$ May 2012, covering the Murrumbidgee floodplain, were downloaded, mosaicked and processed into daily flood maps. Statistics for the whole floodplain as well as two small subsets covering flow gauges 410001 and 410078 (of 5.7 and $24 \mathrm{~km}^{2}$, respectively) were collected in relation to the $\%$ of nulls, clouds, wet and dry pixels. These percentages were combined into 10-day periods to simplify data presentation and summarize the results. Flood extent was also calculated for the two subsets covering the flow gauge sites to enable daily mapped extent to be compared to streamflow. Only the MOD and MYD data with a low view angle (or range distance less than $1000 \mathrm{~km}$ ) were used (Ticehurst et al., 2014).

\subsection{Hydrodynamic model}

The MIKE $21 \mathrm{HD}$ model was used to simulate the Murrumbidgee floodplain. It simulates the water level variation and streamflow in response to a variety of forcing functions in floodplains (DHI, 2009). The model uses the basic principles of conservation of mass and momentum to simulate unsteady floodplain flows in one-layer (vertically homogeneous) (Dutta et al., 2007). The model solves the continuity and momentum equations using an alternating direction implicit technique at each time step (Abbott et al., 1973). The boundary conditions can vary in both time and space, and point sources and sinks can also be incorporated into the model. The input data includes topography (obtained from a digital elevation model (DEM)), boundary conditions, bed resistance (constant or spatially variable), flux or velocity based eddy viscosity, rainfall, evaporation and surface infiltration data varying in time and space. Model output includes spatial and temporal changes of water depth and flow across the modelling domain.

\subsection{Comparison of remote sensing and hydrodynamic modelling flood maps}

The HD model was run on a subset of the Murrumbidgee floodplain at 5-m spatial resolution between flow gauge 410002 and 410136 for the $27^{\text {th }}$ December 2010. A cell-to-cell spatial comparison from the HD model output was compared to both the Landsat and MOD (MODIS morning overpass) data. The MYD (MODIS afternoon overpass) was not used because it had a large view angle.

\section{RESULTS}

\subsection{Landsat and MODIS comparison}

Figure 2 shows the percentage of days for each 10-day period that there is either Landsat, MOD (MODIS morning overpass) or MYD (MODIS afternoon overpass) data in the Murrumbidgee floodplain during the 2010-2011 and 2012 flood events. An image was counted if it had greater than $10 \%$ data in it (i.e. no more than $90 \%$ nulls). Figure 2 shows that there is $100 \%$ MYD coverage for the whole of the floodplain for the duration of the flood periods. There are MOD data for 8 to 9 days of the 10-day periods during the flood events. The other 1 to 2 days contain nulls due to the MODIS orbit pattern and swath coverage over this part of Australia. 


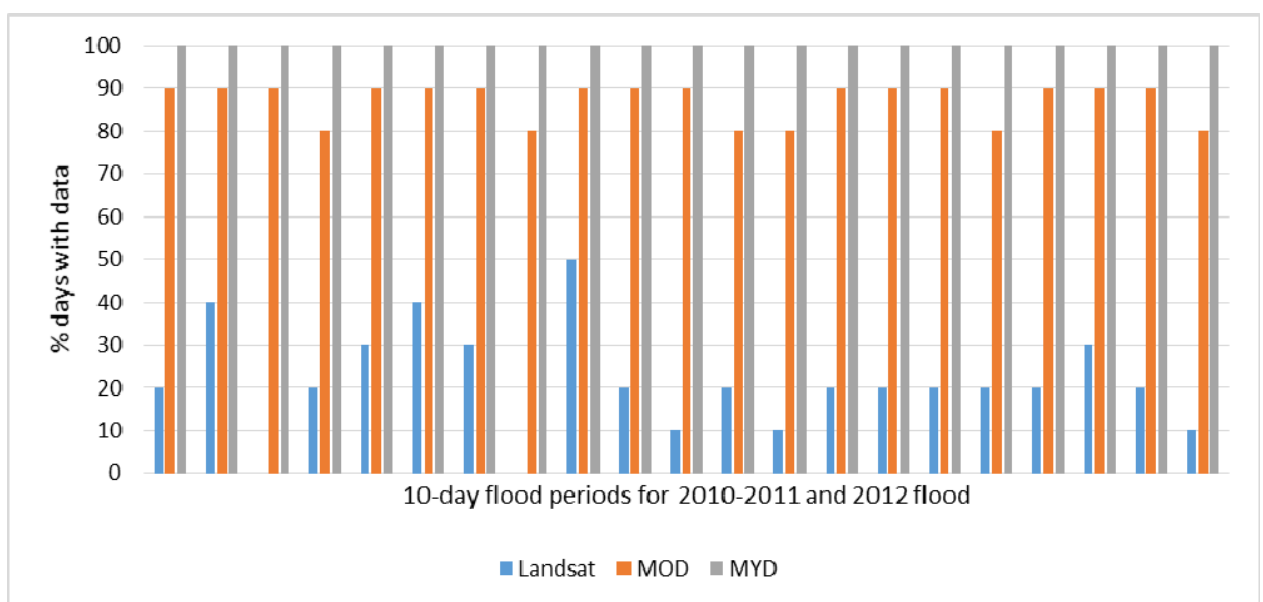

Figure 2. Percentage of days for each 10-day period that there is remote sensing data for the Murrumbidgee floodplain during the 2010-2011 and 2012 flood events.

For Landsat there are only 0 to 5 days of data for the 10-day periods. This is because of the 16-day repeat cycle of the Landsat which greatly reduces it temporal coverage.

For the same 10-day flood periods, the average percentage of nulls, clouds and useable data were calculated for the Landsat, MOD and MYD data for the Murrumbidgee floodplain (Figure 3). The Landsat has many more null pixels (ranging from 30 to $100 \%$ ) compared to the MODIS data. This is again related to the 16-day repeat cycle and the small image extent compared to MODIS. However the average percentage of useable pixels was mostly more than the average percentage of cloudy pixels.

Even though the MYD images had 100\% temporal coverage during the flood periods (Figure 2), it had a higher percentage of cloud cover compared to the MOD images (Figure 3). This is most likely because the MOD overpass occurs around 10am when the weather is more likely to be clear compared to the MYD afternoon overpass (around 2pm).

The mapped flood extent for the Landsat, MOD and MYD are shown in Figure 4 along with streamflow for the two sites at flow gauges 410001 and 410078. Streamflow is used to show an indirect comparison of flood duration and magnitude. As expected, there are fewer days with Landsat flood extents compared to the MOD and MYD data. At flow gauge 410001 there are no useable Landsat data during the 2012 flood period.

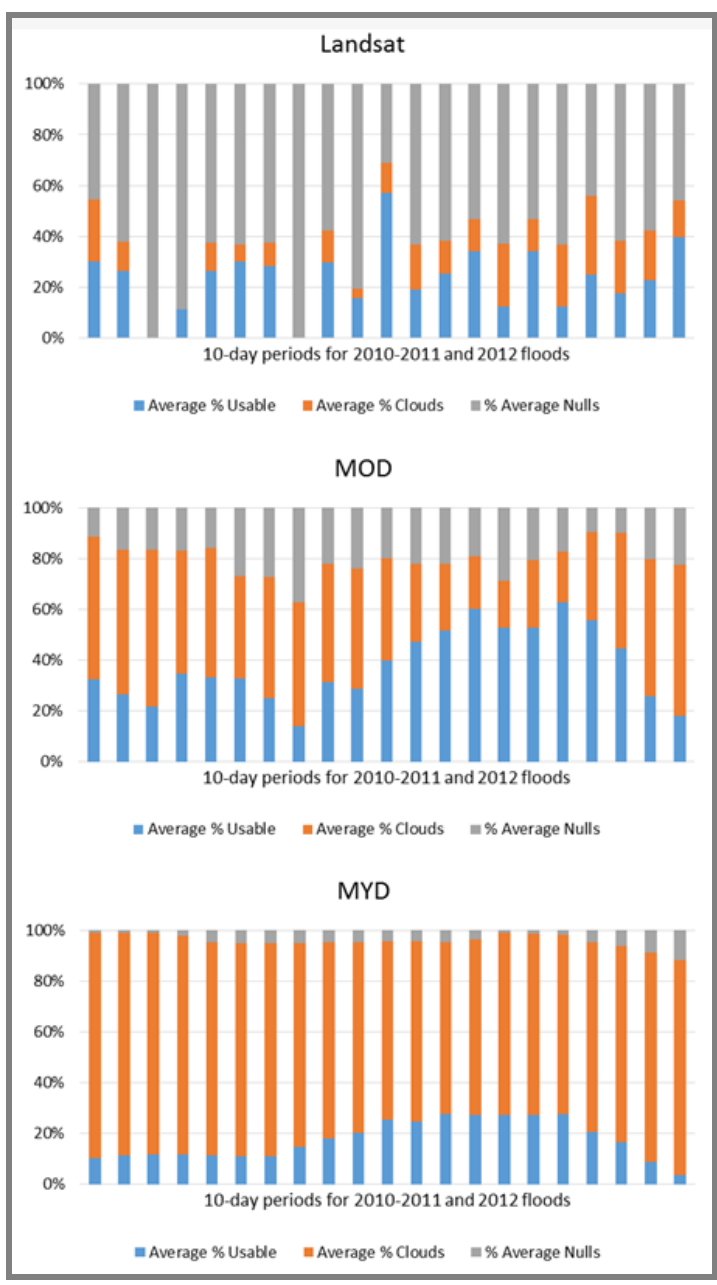

Figure 3. Average percentage of null, clouds and useable data over each 10-day period in the remote sensing data for the Murrumbidgee floodplain during the 2010-2011 and 2012 flood events. 
While the magnitude of flood extents are arbitrary since they are based on the site size, the Landsat data shows a greater flood extent compared to the MOD and MYD data. Furthermore the Landsat flood extents do not map as zero even though the MODIS data does. This is due to the large spatial resolution of the MODIS sensor $(500-\mathrm{m}$ in this case) compared to the Landsat $(30-\mathrm{m})$. The $30-\mathrm{m}$ pixels in the Landsat are able to detect the narrow river channels which always have some water in them. However, when flood maps are produced using the MODIS data, the MODIS OWL pixels calculated to contain less than $5 \%$ water in them were removed to reduce commission errors (Ticehurst et al., 2014). This, along with its large spatial resolution, reduces the ability of the MODIS data to detect fine water features. Even so, both the MOD and MYD data are showing an increase in flood extent when streamflow increases. Interestingly the MOD appears to be mapping less flood extent when compared to the MYD data. Ticehurst et al. (2014) found the MOD and MYD OWL flood extents to be comparable in their analysis, however the discrepancy shown here will be the subject of further investigation.

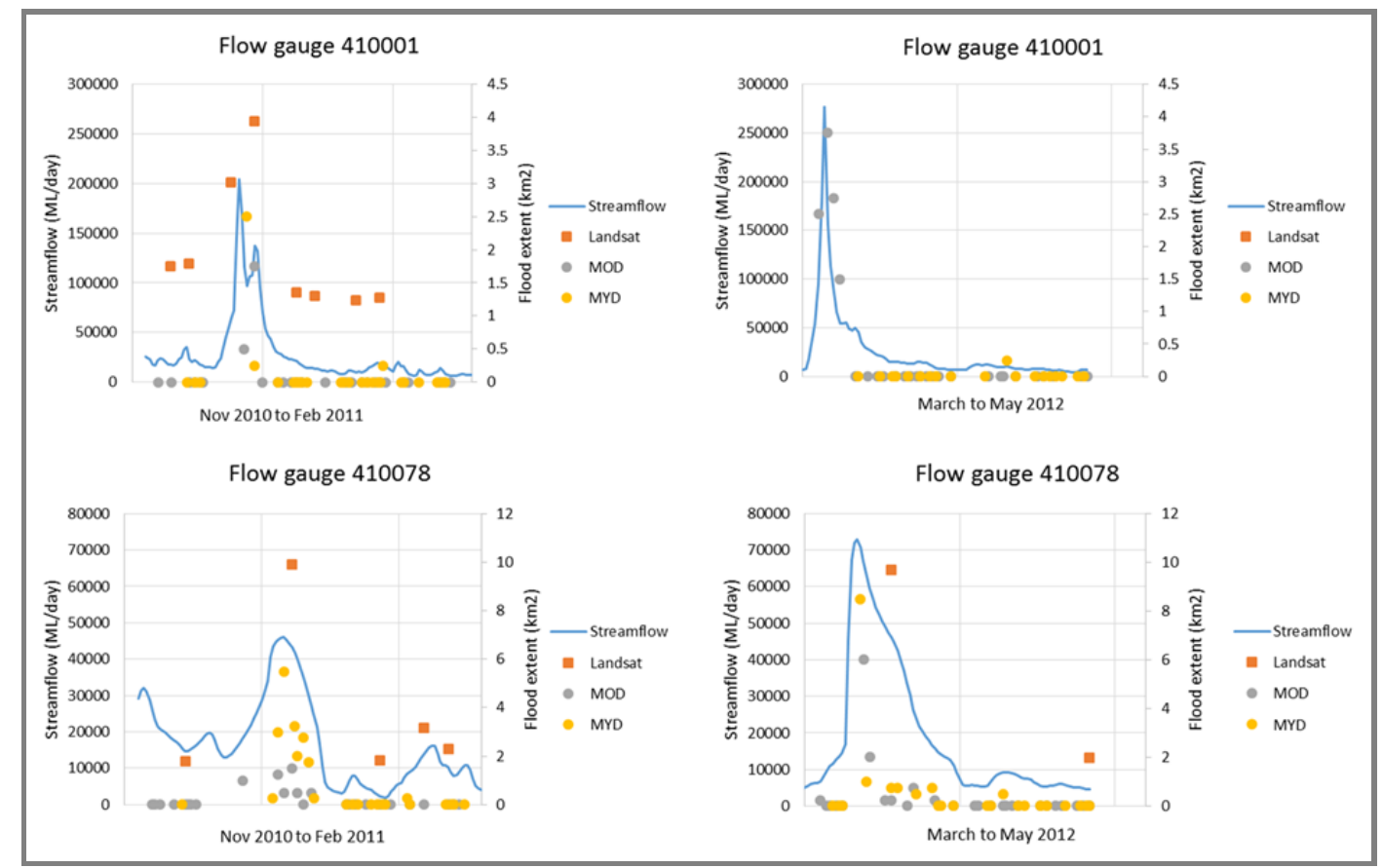

Figure 4. Landsat, MOD and MYD flood extent plotted against streamflow at flow gauges 410001 and 410078 for the 2010-2011 and 2012 flood events.

\subsection{Hydrodynamic modelling and remote sensing comparison}

A spatial comparison of the Landsat and HD model, and MOD and HD model flood maps for the $27^{\text {th }}$ December 2010 is shown in Figure 5. The Landsat flood map is showing a reasonable comparison with the HD model flood map (Figure 5a) with $75 \%$ pixel agreement within the floodplain. The main difference being that the Landsat extent is not as large, particularly along the edge of the flood. The large pixel size of the original MOD flood map $(500 \mathrm{~m})$ means that it is not mapping floods along most of this subset due to the relatively narrow width of the river (Figure $5 b)$ with only a $32 \%$ pixel agreement. This is because the recommended MODIS OWL threshold of $5 \%$ was used (based on the results of Ticehurst et al., 2015) which eliminates pixels containing less than 5\% water in them.

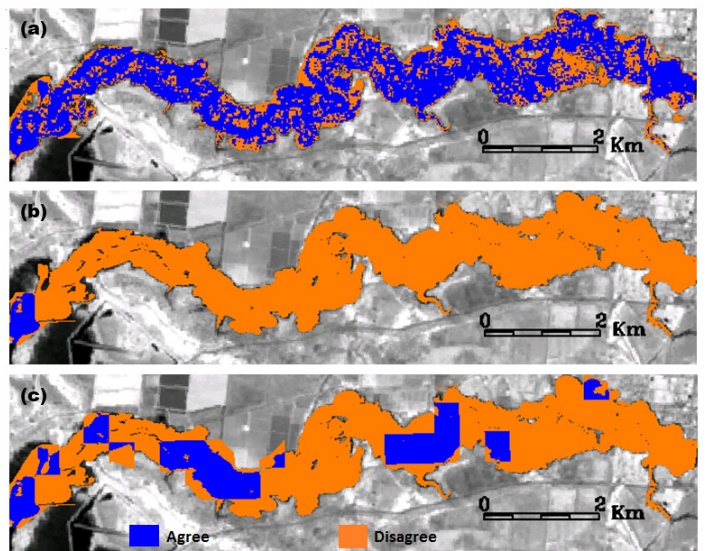

Figure 5. Comparison of Landsat and HD model (a), MOD (5\% threshold) and HD model (b), and MOD (2\% threshold) and HD flood maps for a subset of the Murrumbidgee floodplain. 
However, there were still many MODIS OWL pixels identified as containing some water in them with a 1 to $4 \%$ OWL threshold. Figure 5c shows the MOD flood map based on a $\%$ OWL threshold compared to the HD model. It demonstrates how more pixels can be identified as water when the OWL threshold is reduced with a $43 \%$ pixel agreement within the floodplain, however caution needs to be applied since a lower threshold increases commission errors (Ticehurst et al., 2014).

\section{DISCUSSION AND CONCLUSIONS}

Hydrodynamic and hydrological modelling tools have already proven their effectiveness in producing detailed characteristics of floodplain inundation with a high degree of accuracy. However, the computing time and effort, and fine spatial detail required means they can only realistically cover small spatial extents. Remote sensing data such as Landsat and MODIS can play a role in extending the coverage available for monitoring and mapping flood events. However, both the Landsat and MODIS data have advantages and limitations:

- The spatial and temporal coverage of Landsat data are limited compared to MODIS. This can be a particular problem considering the high proportion of cloud cover often associated with flood periods.

- $\quad$ The MODIS OWL has already shown it has the ability to map large flood events (Ticehurst et al 2013), and it still may provide a good means for identifying, and providing some information on flood duration and magnitude particularly at a daily time-step. However the Landsat data are ideal for mapping the fine spatial details of smaller flood events when available.

- $\quad$ Both the MODIS and Landsat can be used together to create a more accurate picture of the spatial dynamics of a flood event, especially along river systems that include relatively narrow river channels.

Ideally the hydrodynamic model's output can be targeted at key sites for capturing the fine temporal and spatial detail that it offers. This information can then be linked to the Landsat and MODIS remote sensing flood maps to allow for the characterisation of a flood's duration and spatial dynamics at a regional scale.

\section{ACKNOWLEDGMENTS}

This work is carried out in CSIRO Land and Water and is partly funded by AWRA (WIRADA research alliance), MDBA and CSIRO.

\section{REFERENCES}

Bhuiyan, J., and Dutta, D. (2012). Analysis of Flood Vulnerability and Assessment of the Impacts in Coastal Zones of Bangladesh due to Potential Sea Level Rise. Natural Hazards, 61:729-743.

Brakenridge, R., and Anderson, E. (2006). MODIS-based flood detection, mapping and measurement: The potential for operational hydrological Applications. Transboundary Floods: Reducing the Risks through Flood Management, 72:1-12.

Chen, Y., Wang, B., Pollino, C., Cuddy, S., Merrin, L., and Huang, C. (2014). Estimate of flood inundation and retention on wetlands using remote sensing and GIS. Ecohydrology. DOI: 10.1002/eco.1467.

Chen, Y., Huang, C., Ticehurst, C., Merrin, L., Thew, P. (2013). An evaluation of MODIS daily and 8-day composite products for floodplain and wetland inundation mapping. Wetlands, 33:823-835.

Dutta, D., Alam, J., Umeda, K., Hayashi, M. and Hironaka, S. (2007). A two dimensional hydrodynamic model for flood inundation simulation: a case study in the Lower Mekong River basin. Hydrological Processes, 21:1223-1237.

Dutta, D., and Nakayama, K. (2009). Effects of Spatial Grid Resolution on River Flow and Surface Inundation Simulation by Physically Based Distributed Modeling Approach. Hydrological Processes, 23:534-545.

Frazier, P.S., and Page, K.J. (2000). Water body detection and delineation with Landsat TM data. Photogrammetric Engineering and Remote Sensing, 66(12):1461-1467.

Guerschman, J.P., Warren, G., Byrne, G., Lymburner, L., Mueller, N., and Van-Dijk, A. (2011). MODISbased standing water detection for flood and large reservoir mapping: algorithm development and 
applications for the Australian continent. CSIRO: Water for a Healthy Country National Research Flagship Report, Canberra.

Huang, C., Chen, Y., and Wu, J. (2014). Mapping spatio-temporal flood inundation dynamics at large river basin scale using time-series flow data and MODIS imagery. International Journal of Applied Earth Observation and Geoinformation, 26:350-362.

Karamouz, M., Noori, N., Moridi, A., Ahmadi, A. (2011). Evaluation of floodplain variability considering impacts of climate change. Hydrological Processes, 25:90-103.

Karim, F., Dutta, D., Marvanek, S., Ticehurst, C., Petheram, C. (2013). Hydrodynamic Modelling of Potential Impacts of Climate Change on Hydrological Connectivity of Floodplain Wetland, Proceedings of the 20th International Congress on Modelling and Simulation, Adelaide, Australia, 1 - 6 December 2013.

Karim, F., Dutta, D., Mavanek, S., Petheram, C., Ticehurst, C., Lerat, J., Kim, S., Yang, A. (2015). Assessing impacts of climate change and water resources development on floodplains and wetlands in the Flinders and Gilbert Catchments, Australia. Journal of Hydrology, 522:80-94.

Li, F. (2010). ARG25 Algorithm Theoretical Basis Document. Geoscience Australia, Canberra.

McFeeters, S.K., (1996). The use of normalized difference water index (NDWI) in the delineation of open water features. International Journal of Remote Sensing, 17:1425-1432.

Ryu, J-H., Won, J-S., and Min, K.D. (2002). Waterline extraction from Landsat TM data in a tidal flat. A case study in Gomso Bay, Korea. Remote Sensing of Environment, 83:442-456.

Sims, N.C., Warren, G., Overton, I.C., Austin, J., Gallant, J., King, D. J., Merrin, L.E., Donohue, R., McVicar, T.R., Hodgen, M.J., Penton D.J., Chen, Y., Huang, C. \& Cuddy, S. (2014). RiM-FIM Floodplain Inundation Modelling for the Edward-Wakool, Lower Murrumbidgee and Lower Darling River Systems. Report prepared for the Murray-Darling Basin Authority. CSIRO Water for a Healthy Country Flagship, Canberra.

Teng, J., Chiew, F.H.S., Timbal, B., Wang, Y., Vaze, J., Wang, B. (2012). Assessment of an analogue downscaling method for modelling climate change impacts on runoff. Journal of Hydrology, 472-473, pp 111-125. doi:10.1016/j.jhydrol.2012.09.024.

Teng, J., Vaze, J., Dutta, D., Marvanek, S. (2015). Rapid inundation modelling in large floodplains using LiDAR DEM. Water Resource Management, 29(8): 2619-2636.

Ticehurst, C.J., Chen, Y., Karim, F., Dutta, D., Gouweleeuw, B. (2013) Using MODIS for mapping flood events for use in hydrological and hydrodynamic models: Experiences so far. In Proceedings of MODSIM2013, 20th International Congress on Modelling and Simulation, Adelaide, Australia, 1 - 6 December 2013.

Ticehurst, C., Guerschman, J.P., Chen, Y. (2014). The strengths and limitations in using the daily MODIS Open Water Likelihood algorithm for identifying flood events. Remote Sensing, 6:11791-11809, DOI: $10.3390 /$ rs61211791.

Ticehurst, C.J., Dutta, D., Fazlul, K., Petheram, C., Guerschman, J.P. (2015). Improving the accuracy of daily MODIS OWL flood inundation mapping using hydrodynamic modelling. Natural Hazards, 78:803-820.

$\mathrm{Xu}, \mathrm{H}$. (2006). Modification of normalised difference water index (NDWI) to enhance open water features in remotely sensed imagery. International Journal of Remote Sensing, 27(14): 3025-3033. 